\title{
O SUPREMO TRIBUNAL FEDERAL COMO ÁRBITRO OU JOGADOR? AS CRISES FISCAIS DOS ESTADOS BRASILEIROS E O JOGO DO RESGATE
}

\author{
ANDREA DE QUADROS DANTAS ECHEVERRIA ${ }^{1}$ \\ GustaVo FERREIRA RIBEIRO²
}

Resumo: As promessas e os perigos do federalismo, do ponto de vista de sua solidez fiscal, são objeto de vasta literatura. Porém, pouco se evoluiu, no Brasil, na tentativa de se retratar as falhas observadas pelos teóricos do federalismo fiscal em uma matriz de incentivos; no caso, o denominado jogo do resgate. Este artigo elucida, inicialmente, quais os principais instrumentos institucionais e políticos que estabelecem as condições que geram o ciclo vicioso de irresponsabilidade fiscal dos entes subnacionais e subsequentes resgates por parte do ente central, através do jogo do resgate. Na sequência, essa matriz teórica será confrontada com o desenho federalista proposto pela Constituição de 1988 e as alterações legislativas promovidas posteriormente pela Lei de Responsabilidade Fiscal, como forma de correção da perversa matriz de incentivos estabelecida. Além disso, expõe-se as razões do fracasso de referida reestruturação, mediante a inserção de um novo jogador, o Supremo Tribunal Federal, na estrutura do jogo.

Palavras-Chave: Federalismo fiscal. Jogo do resgate. Constituição de 1988. Lei de Responsabilidade Fiscal. Supremo Tribunal Federal.

\footnotetext{
${ }^{1}$ Pesquisadora Visitante na Universidade de Stanford (California, EUA), 2017/2018 e Doutoranda em Direito pelo Centro Universitário de Brasília. Advogada da União, com atuação perante o Supremo Tribunal Federal. andreaqdantas@gmail.com

2 Doutor em Maurer School of Law, Indiana University Bloomington (EUA). Filiado(a) à Instituição UniCEUB, na condição de Professor do Programa de Mestrado e Doutorado em Direito.
} 


\title{
THE SUPREME COURT AS A REFEREE OR A PLAYER? THE BRAZILIAN FISCAL CRISIS AND THE BAILOUT GAME
}

\begin{abstract}
The promises and perils of federalism, from the fiscal perspective, have being largely studied. However, little progress has been made in Brazil in order to picture the failures observed by fiscal federalism theorists into a matrix; in the so-called "bailout game". This paper elucidates the main institutional and political instruments that could establish the conditions that create the vicious cycle of fiscal irresponsibility of subnational entities and the subsequent bailout by the Union, through the bailout game. Subsequently, this theoretical matrix will be confronted with the federalist design proposed by the 1988 Brazilian Constitution and the subsequent legislatives changes promoted by the Fiscal Responsibility Law, in order to correct the established matrix with perverse incentives. In addition, this paper exposes the reasons for the failure of this federalist restructure through the insertion of a new player, the Brazilian Supreme Court, into the game.
\end{abstract}

KEYWORDS: Fiscal Federalism. Bailout game. Fiscal Responsibility Law. Brazilian Supreme Court. 


\section{REVISTA ESTUDOS INSTITUCIONAIS}

\section{INTRODUÇÃO}

Não há ainda um consenso sobre ser o federalismo ${ }^{3}$ a forma ideal de engenharia institucional. Porém, após o processo de redemocratização na América Latina, referido conceito ganha especial relevância, ao ser associado à descentralização de poder, em oposição aos anteriores governos ditatoriais.

No âmbito econômico, apesar de a descentralização fiscal ter sido apresentada como um pilar fundamental para o desenvolvimento dos países ${ }^{4}$, tal prática vem resultando em profundos desequilíbrios, o que impulsiona o governo central a realizar sucessivos resgates financeiros dos entes subnacionais.

Este artigo se concentra inicialmente na análise do jogo do resgate (bailout game), com o intuito de evidenciar os principais fatores de desequilíbrio fiscal vertical ${ }^{5}$. Parte-se da premissa da ação racional dos entes federados, para se revelar a estrutura de incentivos estabelecida, especialmente quanto à possibilidade de deslocamento de custos entre tais entes.

Na segunda parte do artigo, será realizada uma ponderação entre a estrutura teórica e o desenho federalista traçado pela Constituição de 1988. Almeja-se observar se as crises fiscais dos anos 1990 poderiam ser explicadas pela matriz de incentivos descrita no jogo do resgate. Após, passa-se à análise das mudanças normativas visando a solução de tais crises.

Neste ponto, é importante destacar que, embora a relação entre os perigos do resgate financeiro e a estrutura federalista seja bem explorada na doutrina internacional, tal discussão ainda é incipiente no Brasil.

3 O termo federalismo é utilizado aqui seguindo essencialmente a literatura que o identifica com a descentralização, de modo que o federalismo pode ser entendido como um conjunto de práticas que visam distribuir as atividades políticas e econômicas entre os vários níveis de governo (GIBSON, 2004).

4 "Moreover, it is actively promoted as a development strategy by organizations such as the World Bank" (BESFAMILLE; LOCKWOOD, 2008, p. 577-593).

${ }^{5}$ Importante ressaltar que enquanto o desequilíbrio fiscal vertical ocorre entre os níveis de governo (central versus local); o horizontal se restringe ao mesmo nível de governo, em regra entre os governos locais (no caso brasileiro, poderia ocorrer no nível estadual e no nível municipal). Mais especificamente, o desequilíbrio fiscal vertical pode ser definido como a inabilidade de determinado nível governamental financiar seus próprios gastos públicos (WALTER, 2004), o que representa o grau de dependência do ente subnacional quanto às transferências do ente central (RODDEN; WIBBELS, 2002, p. 494-531). De outro lado, o desequilíbrio fiscal horizontal reflete a capacidade de determinada província fornecer serviços públicos a um menor custo, o que levaria a migrações populacionais e desequilíbrios entre províncias (DALBY, 2005, p. 08). 
Nesse contexto, este artigo dialoga com a doutrina internacional que relaciona o resgate do ente central à propensão de crises fiscais, com ênfase no estudo já desenvolvido por Jonathan Rodden. ${ }^{6}$

Por fim, partindo da existência de um novo ciclo de resgaste dos Estados brasileiros e do suposto fracasso das alterações normativas do final da década de 1990, este artigo inova ao inserir na estrutura do jogo do resgate o Supremo Tribunal Federal/ STF como um player.

\section{A ESTRUTURA FEDERALISTA E O JOGO DO RESGATE}

De modo geral, as vantagens do federalismo podem ser observadas sob dois aspectos: o político e o econômico. Politicamente, a descentralização de poder funcionaria como um catalizador da accountability, ao deslocar para o âmbito vertical todas aquelas vantagens propugnadas por Montesquieu quanto à tripartição de poderes e a instituição de freios e contrapesos ${ }^{7}$. Confere-se assim uma maior proteção aos direitos individuais contra o Leviatã estatal.

Sob o aspecto econômico, o sistema federalista pode ser visto como um complexo contrato entre os entes federados. O aumento da eficiência seria resultado de sua capacidade de resolver tanto os problemas de alocação de recursos, assimetria de informação e externalidades, quanto de prevenir comportamentos estratégicos, como no clássico dilema dos prisioneiros.

Entretanto, o que se verifica na prática é que diversos sistemas federalistas vêm sofrendo com as constantes crises fiscais de seus entes subnacionais. Ao retratar as falhas observadas pelos teóricos do federalismo fiscal em uma matriz de incentivos, o denominado jogo do resgate pretende elucidar quais os principais instrumentos institucionais e políticos que estabelecem as condições que geram o ciclo vicioso de irresponsabilidade fiscal, minando o equilíbrio e as vantagens de um sistema federalista.

\footnotetext{
${ }^{6}$ Apesar de a obra do citado autor funcionar como um fio condutor do presente artigo, outras obras nacionais e estrangeiras foram trazidas com o intuito de reforçar tanto a teoria sobre o jogo do resgate, como as nuanças do sistema federativo brasileiro, ampliando dessa forma o debate iniciado por Rodden (2006).

7 Ao promover uma maior aproximação entre governantes e governados, a descentralização seria capaz de ampliar o controle das ações governamentais por parte da população, tornando os governantes mais responsáveis, deslocando as vantagens da existência de freios e contrapesos para o âmbito vertical.
} 


\section{REVISTA ESTUDOS INSTITUCIONAIS}

\section{As promessas e os perigos do Federalismo}

Não se pode falar sobre federalismo sem se citar os clássicos artigos Federalistas, escritos por Alexander Hamilton, James Madison e John Jay (1993). Os autores defendem as vantagens da estruturação de um sistema que permitisse um equilíbrio entre um governo central forte e a manutenção da autonomia aos Estados. Os Federalistas afirmavam que essa descentralização deveria contar com um ponto de ancoragem, que seria o governo central, responsável por "certos interesses gerais que só uma autoridade central pode prover de forma útil" (TOCQUEVILLE, 1961, p. 81).

De outro lado, um dos maiores benefícios propugnado pela descentralização de poder seria o aumento da accountability, o qual ocorreria em duas vertentes: na eficiente utilização dos recursos (eficiência alocativa), pois os governos subnacionais, estando mais próximos da população seriam mais capacitados para entender e suprir seus interesses; e no maior controle popular sobre a correta aplicação dos recursos públicos (RIGOLON; GIAMBIAGI, 1999, p. 114). Nesse contexto, seria razoável supor que esse duplo efeito da accountability também seria capaz de produzir reflexos positivos sobre o equilíbrio fiscal.

Entretanto, Hamilton já apontava o risco de desequilíbrio fiscal vertical como uma consequência do potencial enfraquecimento do governo central diante de uma excessiva descentralização, tornando ineficiente o sistema federalista. Isso ocorreria porque a restrição da autonomia do governo central o impediria de promover o indispensável controle dos entes subnacionais, tanto em termos fiscais, como na coordenação de políticas públicas destinadas a prover bens coletivos (RODDEN, 2006, p. 05) ${ }^{8}$.

Portanto, o grande desafio do federalismo é conseguir estabelecer um equilíbrio entre os movimentos centrífugo e centrípeto de poder ${ }^{9}$. Para a teoria econômica, a otimização dos benefícios do federalismo implica uma racional alocação de responsabilidades entre os níveis governamentais (FILIPOV; ORDERSHOCK; SHVETSOVA, 2004, p. 02), a qual não poderia ser efetivada se o ente subnacional possui uma restrição orçamentária flexível (INMAN, 2003, p. 35).

\footnotetext{
8 Nas palavras dos Federalistas (1993, p. 132), a descentralização de poder iria transformar o "império em um corpo sem nervos, incapaz de dirigir seus próprios membros, inseguro contra os perigos externos e agitados por incessantes fermentações em suas próprias entranhas".

${ }^{9}$ Para fins do presente artigo, entende-se que um movimento centrípeto na estrutura federativa promove uma maior centralização de competências, conferindo maior poder ao ente central. Em sentido oposto, o movimento centrífugo representa a descentralização de poder para os entes subnacionais.
} 


\section{O SUPREMO TRIBUNAL FEDERAL COMO ÁRBITRO OU JOGADOR?}

A flexibilidade orçamentária é a capacidade de determinado ente federado manipular seu acesso a recursos, além do orçamento previamente determinado (CABRAL, 2015, p. 244). Ela é apontada como uma das principais causas de indisciplina fiscal e do aumento desordenado do gasto público dos entes subnacionais.

Parte-se dos pressupostos de que a eficiente alocação de recursos exige que todos os custos e benefícios da ação política sejam internalizadas e de que o ente central deve ser o responsável por induzir os governos subnacionais a fornecerem o nível eficiente de serviços públicos (INMAN, 2003, p. 36). O deslocamento de custos torna-se uma variável indispensável na análise do endividamento dos entes subnacionais e das consequentes crises fiscais.

Tal traslado pressupõe que quem arcará com os custos daquela opção política não serão os atuais residentes de determinado ente federado, o que gera uma externalidade negativa ${ }^{10}$. Essa externalidade pode ocorrer tanto na esfera geográfica, quando os custos de determinada ação serão suportados por cidadãos não residentes; como no âmbito temporal, em que se posterga para um período futuro o pagamento de tais custos ${ }^{11}$.

Referido deslocamento de custos pode ser instrumentalizado por meio de transferências de verbas do ente central, nas quais há uma redistribuição geográfica dos custos de arrecadação de tais recursos. Igualmente por meio da formalização de empréstimos, o que pode gerar não apenas um deslocamento temporal, como também um efeito geográfico, no caso em que o ente central opta por assumir referida dívida; o resgate (INMAN, 2003, p. 36).

Nessa hipótese, partindo da premissa de que o interesse primordial dos parlamentares é a reeleição ${ }^{12}$, a ação racional que se espera deles é aquela que visa ampliar a destinação de recursos para seus eleitores e,

\footnotetext{
${ }^{10} \mathrm{Na}$ teoria econômica, o surgimento de uma externalidade ocorre quando um agente não usufrui todos os benefícios (externalidade positiva) ou suporta todos os danos (externalidade negativa) resultantes das ações por ele realizadas (BAIRD; GERTNER; PICKER, 1994, p. 162).

${ }^{11}$ Isso ocorre quando o ente federado recorre a empréstimos para o pagamento de despesas correntes atuais. Nessa hipótese, os atuais residentes irão usufruir dos benefícios gerados pelo aumento de recursos, entretanto tais custos serão distribuídos no tempo.

${ }^{12}$ Tal premissa foi desenvolvida inicialmente por Antony Downs, no clássico livro “Uma Teoria Econômica da Democracia" e seguida por vários outros autores que analisam comportamento eleitoral (MANIN; PRZEWORSKI; STOKES, 1999, p. 32). Ademais, ainda que a premissa do modelo de Down seja contestável, o aumento de orçamento é sempre um objetivo buscado pelos agentes políticos; "[n]o matter what the goals of subnational officials, greater revenue relaxes their budget constraint, allowing them to further their goals" (WEINGAST; FIGUEIREDO JR., 2005, p. 112)
} 


\section{REVISTA ESTUDOS INSTITUCIONAIS}

sempre que possível, reduzir os custos dessas ações. Assim, os eleitores sentirão apenas os seus benefícios. Entretanto, os custos certamente virão, recaindo sobre os eleitores de outros entes federados ou sobre futuros eleitores.

A possibilidade de deslocamento de parte dos custos irá provocar uma disparidade na percepção da relação entre os custos e os benefícios de determinada política pública, levando os entes subnacionais a aumentarem os gastos locais. Assim, embora tais estratégias de aumento de recursos sejam preferíveis sob o enfoque dos entes subnacionais, são socialmente ineficientes ${ }^{13}$, pois geram uma externalidade negativa ${ }^{14}$ sem a devida análise de seus efeitos colaterais. Em outras palavras, como os custos não serão suportados pelo ente que escolheu referida ação política, há uma tendência em que todos os Estados produzam ações similares, visando deslocar os custos geográfica ou temporalmente. Ademais, o deslocamento de custos torna o controle da ação política mais complexa e, portanto, mais difícil por parte dos eleitores, reduzindo assim a accountability.

De forma semelhante, a possibilidade de resgates pelo ente central também tende a gerar ineficiência na alocação de recursos. Na sequência, a matriz do jogo do resgate irá fornecer importantes indícios de como a estrutura federalista pode induzir tanto a irresponsabilidade fiscal dos entes subnacionais, como também indesejáveis ciclos de resgates.

\section{O jogo de resgate (bailout game)}

Como visto, além de sua conformação política, o federalismo pode ser visto sob o aspecto econômico como um contrato entre os entes federados. No caso da interação entre entes federados, e considerando tanto a impossibilidade de uma das partes simplesmente sair do jogo, como o enfoque fiscal conferido por esse artigo, descreveremos esta dinâmica pelo jogo do resgate ${ }^{15}$.

\footnotetext{
13 Para análise gráfica da ineficiência gerada pelo deslocamento de custos ver figura 2.1 em Inman (2003, p. 37).

${ }^{14} \mathrm{O}$ autor usa o termo fiscal spillover que seria uma externalidade negativa no âmbito orçamentário, "fiscal spillovers, created when local or state governments shift the budgetary costs of their own expenditures onto nonresidents, current or future" (INMAN, 2003, p. 36)

${ }_{15} \mathrm{O}$ jogo do resgate utilizado nesse artigo espelhou-se na estrutura desenvolvida no capítulo 3 de Rodden (2006, p. 50-55). Com o intuito de evitar excessivas referências ao citado autor, serão destacadas somente as contribuições de outros autores sobre o esquema já desenvolvido pelo autor.
} 


\section{O SUPREMO TRIBUNAL FEDERAL COMO ÁRBITRO OU JOGADOR?}

Suponha-se, então, um jogo entre o ente central e um único ente subnacional, no qual ambos os governantes, agindo de forma racional, estão interessados no impacto de suas escolhas fiscais sobre uma suposta reeleição. Portanto, pretendem maximizar os benefícios e minimizar os custos de suas decisões políticas. Deve-se considerar que um ajuste fiscal sempre impõe custos ao ente subnacional, tanto à sua autoridade como à sua população, uma vez que, em regra, tal ajuste é realizado mediante o aumento de impostos e/ou a redução de gastos públicos. Nesse contexto, como já discutido, o ente subnacional irá procurar redistribuir tais custos pelos demais entes da federação.

Em um primeiro momento, pode-se entender tal jogo como sendo de informação incompleta, eis que o ente subnacional ainda não conhece o tipo de jogador que é o ente central. $\mathrm{O}$ ente subnacional desconhece se, em caso de crise fiscal, o ente central o deixará falir (não resgate) ou se arcará com suas dívidas (resgate).

Diante da primeira crise fiscal, o ente subnacional tem duas opções: fazer o ajuste imediato (AI) e arcar com os custos sociais e políticos de tal decisão, encerrando aquela jogada; ou solicitar mais recursos (SR), mediante empréstimos ou transferências, para tentar contornar a crise.

O ente central, por sua vez, poderá socorrer o ente subnacional, o que encerra o jogo no denominado resgate imediato (RI); ou quedar-se inerte e não resgatar (NR). Nesse último caso, tem-se a segunda rodada no jogo, na qual, apesar da elevação dos riscos diante do provável aprofundamento da crise, as opções de ações dos entes se mantem inalteradas.

Do ponto de vista dos entes subnacionais, embora um resgate tardio (RT) não seja tão favorável, o pior cenário seria a falência (FAL), diante da impossibilidade de se realizar um ajuste tardio (AT). Nesse contexto, a função utilidade (U) dos entes subnacionais (s) pode ser assim escalonada:

$$
\text { Us }(\mathrm{RI})=1>\mathrm{Us}(\mathrm{RT})>\mathrm{Us}(\mathrm{AI})>\mathrm{Us}(\mathrm{AT})>\mathrm{Us}(\mathrm{FAL})=0 \text {. }
$$

De outro lado, os interesses do ente central são mais complexos de serem escalonados. Embora sua preferência seja sempre por um ajuste imediato por parte do ente subnacional, o que evita o ineficiente deslocamento de custos, não é tão clara sua opção entre promover um resgate tardio ou a falência de determinado ente subnacional. Nesse sentido, pode-se estabelecer dois tipos de ente central, o resoluto (cr), que nunca irá realizar o resgate; e o irresoluto (ci), que poderá resgatar. 


\section{REVISTA ESTUDOS INSTITUCIONAIS}

$\mathrm{O}$ ente central resoluto (não-resgate) teria a seguinte função de utilidade, na qual é preferível que o ente subnacional decrete sua falência a que o ente central realize alguma espécie de resgate:

$\operatorname{Ucr}(\mathrm{AI})=1>\operatorname{Ucr}(\mathrm{AT})>\operatorname{Ucr}(\mathrm{FAL})>\operatorname{Ucr}(\mathrm{RI})>\operatorname{Ucr}(\mathrm{RT})=0$

Já um ente central irresoluto (disposto a resgatar) teria a função de utilidade alterada, da seguinte forma:

$$
\operatorname{Uci}(\mathrm{AI})=1>\operatorname{Uci}(\mathrm{AT})>\operatorname{Uci}(\mathrm{RI})>\operatorname{Uci}(\mathrm{RT})>\operatorname{Uci}(\mathrm{FAL})=0 \text {. }
$$

A princípio, o ente subnacional não sabe exatamente quais são as preferências do ente central, embora a cada rodada possa haver uma sinalização deste. Ao contrário das teorias clássicas sobre federalismo fiscal que afirmavam que os entes subnacionais agiam de conformidade com a política fiscal instituída pelo ente central (WILDASIN, 1997, p. 9 e 23); na teoria do jogo do resgate, o líder é o ente subnacional (ES), o qual será responsável pelo primeiro movimento, consoante se observa da estrutura abaixo desenvolvida por Rodden:

\section{Figura1 - Grafo do Jogo do Resgate}

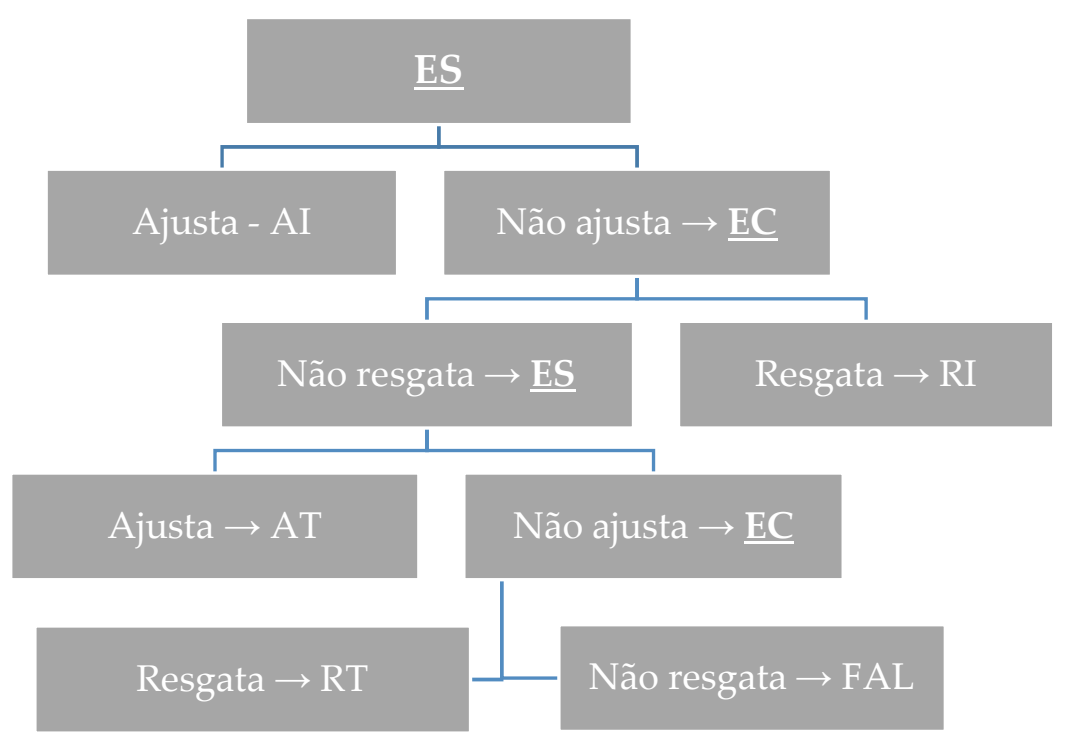

Fonte: baseado em Rodden (2006)

4 JOURNAL OF INSTITUTIONAL STUDIES 2 (2018)

Revista Estudos Institucionais, v. 4, n. 2, p. 642-671, 2018 
Como em todo jogo sequencial, sua solução é mais facilmente encontrada pelo mecanismo de indução reversa (backwards induction), o que torna evidente a importância do ente subnacional conhecer a espécie de ente central com o qual interage. Assim, o nível de incerteza sobre o comprometimento do ente central com eventual resgate irá impactar diretamente a matriz de incentivos dos entes subnacionais. Se esses acreditam que o ente central não irá realizar o resgate, a indução reversa do jogo indica que não há espaço para o comportamento oportunista dos entes subnacionais, que deverão realizar o ajuste imediato. De outro lado, se os entes subnacionais sabem que o ente central será obrigado a realizar o resgate, o ajuste não será realizado e o jogo deveria terminar com um resgate imediato.

Entretanto, considerando que a preferência primordial do ente central - seja ele do tipo resoluto (não resgate) ou irresoluto (resgate) - é pela realização do ajuste pelo ente subnacional, a ação racional do ente central é negar o resgate nas primeiras rodadas, tentando sinalizar como sendo do tipo resoluto, com o intuito de induzir o ajuste pelo ente subnacional.

Desse modo, nas primeiras rodadas do jogo, diante da incerteza da espécie de ente central, o ente subnacional deverá decidir sua ação com fundamento na probabilidade de resgate por parte do ente central. Ou seja, se o ente subnacional acredita que o ente central irá realizar o resgate, ele arriscará e não realizará o ajuste; caso contrário, se há indícios suficientes de que o ente central é resoluto e não irá resgatar, a tendência é que o ente subnacional realize o ajuste, ainda que de forma tardia. No limite, o ente subnacional poderá decretar sua falência, como ultima ratio na tentativa de forçar um resgate do ente central, que poderá ou não realizá-lo. A efetiva falência do ente subnacional somente deveria ocorrer quanto esse se equivoca quanto à espécie de ente central.

Torna-se, agora, indispensável identificar quais os fatores institucionais e estruturais que alteram a probabilidade de comprometimento do ente central em não efetuar o resgate, de modo que o aumento da probabilidade de não resgate gerada pela estrutura federalista estaria diretamente relacionado com a disciplina fiscal dos entes subnacionais.

\section{Construindo incentivos para o resgate}

Como visto, o grande dilema sobre o qual se fundamenta o citado jogo refere-se à possibilidade de o ente central efetuar ou não o resgate, e como tal informação pode ser obtida pelos entes subnacionais. 


\section{REVISTA ESTUDOS INSTITUCIONAIS}

Um primeiro fator essencial é saber como os entes subnacionais poderão angariar recursos a pós a primeira rodada do jogo, quando o ente central lhes nega o resgate, sendo as formas mais usuais o empréstimo, as transferências de verbas e o aumento de tributos.

Quanto aos empréstimos, a autonomia dos entes subnacionais pode existir tanto no âmbito interno, como no caso da existência de bancos estaduais, como também no plano internacional, caso os entes subnacionais tenham acesso direto a empréstimos no exterior, sem a necessidade de uma autorização ou garantia expressa do ente central. Referida autonomia reduz os custos do ente subnacional de, na primeira rodada do jogo, optar por ajuste imediato, dada a facilidade de acesso a crédito que os permita postergar o ajuste fiscal. De outro lado, observa-se um aumento mais vertiginoso dos riscos em se adiar o ajuste fiscal, considerando que empréstimos sucessivos, sem o correspondente reequilíbrio dos gastos públicos, tendem a aprofundar as crises fiscais.

No que se refere à questão tributária, o grau de autossuficiência financeira dos entes subnacionais é mais importante do que a autonomia tributária ${ }^{16}$, pois permite que os eleitores identifiquem a relação entre o pagamento de tributos e os serviços prestados. Essa correlação permite o tão propalado aumento da accountability e uma consequente maior disciplina fiscal dos entes subnacionais, aumentando a eficiência da estrutura federalista (INMAN, 2003, p. 36).

Por fim, a transferência de recursos no sistema federalista é vista como um importante instrumentos de redistribuição de renda para as regiões mais carentes, como uma tentativa de equalização dos recursos entre os entes da Federação. Apesar de tal relevância estrutural, a excessiva dependência do ente subnacional de recursos do ente central, também denominada de desequilíbrio fiscal vertical, é identificada como um dos fatores que reduzem a probabilidade de não resgate ${ }^{17}$.

Isso ocorre não apenas em razão do deslocamento de custos que, como visto induziria o aumento desordenado de gastos públicos, como também porque a centralização de recursos promove uma consequente transferência da responsabilidade financeira para o ente central. Quando os entes subnacionais passam a depender de recursos do ente central para

\footnotetext{
${ }^{16}$ A competição entres os entes subnacionais (a denominada guerra fiscal) seria capaz de impedir uma autonomia tributária absoluta.

17 Nesse sentido, "[a] key argument in this chapter is that when subnational governments depend heavily on intergovernmental grants, loans, and revenuesharing schemes as opposed to subnational taxes and fees, the central government's ex ante commitment to a policy of "no bailouts" lacks credibility" (RODDEN, 2006, p. 92). No mesmo sentido, "[e]mpirically it was found that grants stimulate more spending than a simple increase in income for the community" (GOODSPEED et al., 2016, p. 04).
} 
cumprir com as funções e as competências lhe foram delegadas, há uma redução da responsabilidade fiscal, fundamentada na crença de que o governo central deve prover essa ajuda econômica, pois não há uma efetiva autonomia financeira dos entes descentralizados. Tem-se, assim, a transformação do ente central em uma espécie de garantidor implícito da saúde financeira dos entes subnacionais (RODDEN, 2006, p. 91), o que reduz drasticamente a probabilidade de não resgate.

De outro lado, a própria população não consegue mais identificar qual a esfera responsável pela consecução das políticas públicas, o que afeta o controle social sobre a aplicação dos recursos, reduzindo a accountability, e consequentemente, a disciplina fiscal ${ }^{18}$.

Observa-se que o equilíbrio entre os movimentos centrípeto e centrifugo é tão tênue que tanto o excesso como a falta de autonomia tendem a gerar o mesmo efeito perverso. Entretanto, pode-se afirmar que o mais perigoso desequilíbrio é aquele gerado pela combinação de autonomia financeira para obter empréstimos com um alto desequilíbrio vertical fiscal, que torna o ente subnacional ao mesmo tempo dependente de transferências de recursos do ente central, mas autônomo para contrair dívidas (RODDEN, 2006, p. 93). Nesse caso, tem-se a ocorrência simultânea de dois mecanismos de deslocamento de custos, sem os instrumentos fiscais de controle necessários para impedir o aumento desornado de gastos públicos.

Decerto, a estrutura federalista pode ser desenhada das mais diversas formas. A simples descentralização de poder não é, porém, condição única e suficiente para a garantia do equilíbrio fiscal. Como visto, diversos mecanismos (tamanho dos entes subnacionais, percepção dos eleitores e do próprio ente quanto ao resgate) tendem a gerar um desequilíbrio fiscal, em face do excessivo deslocamento de custos.

Resta analisar o desenho federalista brasileiro com o intuito de identificar a existência de falhas institucionais que possam explicar as sucessivas crises fiscais brasileiras, com base na teoria delineada.

\section{A ESTRUTURA FEDERALISTA BRASILEIRA}

A estrutura constitucional não é capaz, por si só, de estabelecer o sistema federalista, cujo funcionamento dependerá também da complexa estrutura de poder político e econômico. Emerge a importância da análise não apenas da estrutura federalista prevista na Constituição Federal, mas também das forças reais de poder que participaram da Assembleia

18 Rodden denomina de ilusão fiscal essa impossibilidade de o eleitor conseguir identificar a esfera governamental responsável pela provisão dos serviços locais (RODDEN, 2006, p. 95). 


\section{REVISTA ESTUDOS INSTITUCIONAIS}

Constituinte no momento do redesenho institucional do federalismo no Brasil.

Além do comportamento dos entes federados, que será examinado no cotejo entre o arcabouço teórico federalista e o jogo do resgate, também será objeto dessa seção as mudanças normativas inseridas após as crises fiscais dos anos 1990, que visaram alterar a matriz de incentivos do federalismo brasileiro, de modo a induzir a responsabilidade fiscal (Lei de Responsabilidade Fiscal/LRF).

\section{A Constituição de 1988: As promessas e os perigos do federalismo fiscal}

Sobre as ruínas do federalismo brasileiro, herança de uma excessiva centralização da ditadura militar (ABRUCIO, 1994, p. 167), foi erguida a nova estrutura federativa do país, motivada pelo sentimento de redemocratização. Já durante a Assembleia Constituinte, apesar dos anseios descentralizadores, a tradição de um federalismo centralizado não permitiu uma descentralização de competência e recursos como inicialmente pretendida.

Diante da ausência de maiores disputas no âmbito das subcomissões responsáveis pela definição de competências legislativas ${ }^{19}$, manteve-se a tendência de centralização de tais competências na União, a qual possuía a maior quantidade de competências exclusivas, sob o argumento da indispensável uniformização de regras.

De outro lado, embora a opção constituinte pelo princípio da solidariedade tenha gerado o compartilhamento da responsabilidade na provisão dos serviços públicos entre as três esferas governamentais, a ausência de uma definição clara sobre as competências específicas de cada ente, confirmou que a estrutura federalista deveria ser fluida o

\footnotetext{
${ }_{19}$ Uma questão fundamental foi o desmembramento das comissões, de modo que as subcomissões responsáveis pelas competências legislativas eram autônomas em relação às que iriam regulamentar a distribuição de recursos, fazendo com que o desenho das relações intergovernamentais, e os possíveis conflitos daí decorrentes, fosse feito sem a devida atenção e discussão. Nesse sentido: "Sigmaringa Seixas afirmou que não sofreu pressões, seja de governadores, prefeitos ou de corporações, declarando que "eu achava que não tinha nenhum prestígio porque ninguém me pressionava" (entrevista em 13/5/1993), creditando a falta de pressão ao fato de essa subcomissão não lidar com distribuição de recursos financeiros" (SOUZA, 2001, p. $522)$.
} 
suficiente a permitir a alocação de serviços em qualquer dos níveis de governo ${ }^{20}$.

Como resultado, houve ampliação das responsabilidades da União especialmente na área social, em aparente paradoxo com a intuito descentralizador dos constituintes (SOUZA, 2001, p. 525).

As discussões dos efeitos da descentralização dominariam, então, as subcomissões responsáveis pela distribuição tributária e financeira. Aliás, o objetivo principal da Subcomissão do Sistema Tributário e da Divisão e Distribuição de Receitas era exatamente a descentralização da capacidade tributária dos impostos mais produtivos, o que foi apresentado como uma solução tanto para os problemas financeiros dos entes federados como também para outros importantes impasses, como os atrasos burocráticos e a própria corrupção. Como resultado, tem-se o seguinte aumento estadual e municipal no produto final da arrecadação: "os municípios passariam de $17.7 \%$ para $24 \%$. Os Estados, de $37.4 \%$ para $40 \%$. E a União cairia de 45 para 36 pontos percentuais" (BRASIL, 1987, p. 98) ${ }^{21}$.

A Constituição de 1988 estabeleceu, assim, duas forças contraditórias ao descentralizar os recursos federais e centralizar as competências legislativas na União (SOUZA, 2005, p. 112), produzindo um desequilíbrio entre os movimentos centrífugo e centrípeto, essenciais na presente análise. Ressalta-se que, mesmo a descentralização financeira foi marcada pela prevalência de transferências constitucionais de recursos em detrimento à arrecadação dos tributos pelos próprios entes federados.

Embora essas transferências de recursos tenham um relevante caráter redistributivo, o que demonstra uma preocupação com as áreas menos desenvolvidas do país, não há como negar seu efeito pernicioso que promove tanto a redução da accountability do governo local, como uma tendência de aumento dos gastos públicos, diante da redistribuição de responsabilidade para a União. No caso, apesar das disparidades no percentual de dependência dos Estado brasileiros, a fluidez da competência para a prestação dos serviços públicos somada à dificuldade de acesso à informação pela maior parte da população acabam por gerar

\footnotetext{
${ }^{20}$ Nesse contexto, uma questão interessante foi a rejeição pela Subcomissão dos Estados da proposta feita pela Subcomissão de Municípios e Regiões de delegar a competência de 14 serviços públicos para a esfera municipal. "Assim, a tensão entre facilitar a cobrança do serviço público pelo cidadão e a necessidade de deixar flexível a alocação de funções entre os níveis de governo em um sistema federal foi resolvida a favor da última alternativa" (SOUZA, 2001, p. 523). No mesmo sentido, Abrucio (1994, p. 172).

${ }^{21}$ Dados retirados da discussão da Assembleia Constituinte. Embora haja divergências sobre referido percentual, há um consenso sobre a perda de arrecadação da União promovida pela Constituição de 1988.
} 


\section{REVISTA ESTUDOS INSTITUCIONAIS}

tais efeitos mesmo naqueles Estados em que o percentual de receita própria é superior ao das transferências.

Por fim, embora a questão acerca da autonomia para solicitar empréstimo não esteja delineada na Constituição de 1988, é crucial destacar que à época os Estados detinham ampla autonomia nessa esfera, não havendo necessidade de autorização ou garantia da União para tanto (TAVARES, 2005, p. 84).

Criou-se assim uma perigosa simbiose entre os entes estaduais e a União, uma vez que a descentralização dos recursos não foi seguida da indispensável transferência da responsabilidade fiscal sobre tais recursos, tanto pela ausência de autonomia arrecadatória como também de instrumentos de controle fiscal, concretizando, dessa forma, o paradoxo que seria a semente das futuras crises fiscais.

\section{O jogo do resgate brasileiro}

Do cotejo da estrutura descrita nos tópicos anteriores e do federalismo desenhado na Constituição de 1988 é possível perceber a presença de praticamente todos os fatores que aumentam a possibilidade de resgate por parte do ente central. De fato, o arcabouço constitucional brasileiro apresentava a perigosa mistura de uma ampla autonomia para contrair empréstimos com uma baixa capacidade de arrecadação de recursos, além de uma excessiva centralização de competências legislativas e de serviços no âmbito da União.

Apesar da usual crítica à centralização excessiva, o estudo da Constituinte demonstra que os parlamentares optaram por essa estrutura, com enfoque na descentralização mediante transferências constitucionais obrigatórias. Tal sistema reflete uma escolha racional dos legisladores, em especial dos governadores - então denominados Barões da Federação (ABRUCIO, 1994, p. 165-190) -, diante dos incentivos decorrentes do deslocamento de custos provocado por essa espécie de receita. Ao transferir a responsabilidade de arrecadação para o ente central, mas garantir o repasse obrigatório de percentual de tais recursos, os Estados federados deslocaram para a União tanto os custos de cobrança dos tributos como aqueles custos adicionais proveniente da necessidade de aumento tributário em caso de ajustes fiscais.

Outro fator que colaborava para a ocorrência de um desequilíbrio fiscal vertical era a ampla autonomia para contrair empréstimos, especialmente pela existência dos bancos estaduais que financiavam diretamente os governos locais, sem controle da autoridade fiscal central (TAVARES, 2005, p. 85). Como resultado, a estrutura federalista fiscal proporcionava uma multiplicidade de fontes de financiamento para os 
governos estaduais (RIGOLON; GIAMBIAGI, 1999, p. 128; LOPREANO, 2010, p. 125), incentivando o aumento do gasto público.

Além dessas problemáticas, a desigual descentralização promovida pela Constituição de 1988, ao concentrar a competência legislativa na União e não definir claramente a repartição dos serviços públicos, acabou por centralizar as responsabilidades fiscais e sociais na figura do ente central. Assim, no cenário de crises locais, "os olhos dos eleitores e dos credores irão mover-se rapidamente em direção ao ente central, e não para os governos locais, em busca de soluções" (RODDEN, 2006, p. 96).

As crises fiscais dos Estados brasileiros não tardaram a eclodir. De fato, a ampla autonomia dos Estados para contrair empréstimos em conjunção com a sua alta dependência das transferências de recursos do ente central gerou uma insustentável dívida estadual e municipal, que culminou com o resgate de 25 dos 27 Estados e mais de 150 dos maiores municípios, ao custo aproximado de $\mathrm{R} \$ 100$ bilhões de reais, que representava, em dezembro de 1998, 11,3\% do PIB e 77,9\% da dívida líquida dos Estados e municípios (RIGOLON; GIAMBIAGI, 1999, p. 132).

Assim, apesar dos esforços, o desenho da Constituição de 1988 manteve os incentivos de uma cultura política-administrativa de indisciplina fiscal (TAVARES, 2005, p. 85). Ao colocar a União na posição de garantidora do federalismo brasileiro, gerou a ineficiente matriz do jogo do resgate.

Nesse contexto, tornou-se indispensável reestruturar o desenho federalista brasileiro, com o intuito de alterar a citada matriz de incentivo ao comportamento oportunista dos Estados. Tal mudança seria realizada pela aprovação de uma nova legislação fiscal, focada especialmente na necessidade de reduzir o acesso dos entes subnacionais a recursos públicos e de vetar a possibilidade de resgate por parte da União. No próximo item tais inovações normativas serão contrastadas com aquela estrutura de incentivos prevista no jogo do resgate, com o intuito de verificar se o resultado do jogo poderia realmente ser alterado.

\section{Um federalismo melhor? Reduzindo a probabilidade de resgate}

Após o refinanciamento das dívidas dos Estados no final dos anos 1990, ficou clara a necessidade de se reestruturar o federalismo fiscal 


\section{REVISTA ESTUDOS INSTITUCIONAIS}

brasileiro, o que foi feito mediante uma série de alterações legislativas e constitucionais ${ }^{22}$, visando especialmente o fortalecimento da União ${ }^{23}$.

Para que a matriz do jogo do resgate pudesse ser efetivamente desconstruída, "a primeira linha de defesa do ente central é tornar crível seu compromisso com o não resgate" (RODDEN, 2006, p. 110), o que foi efetivado mediante a promulgação da Lei de Responsabilidade Fiscal/LRF (LC no 101/200), a qual vetava a possibilidade de novos refinanciamentos da dívida estadual pela União. Já a segunda linha de defesa deveria focar na redução do desequilíbrio fiscal vertical, mediante a imposição de sérias restrições aos gastos públicos e ao acesso ao crédito.

Nesse sentido, a privatização dos bancos estaduais reduziu drasticamente a autonomia dos Estados para contrair empréstimos internamente, extinguindo o que era considerado um dos fatores essenciais do endividamento dos entes subnacionais (RODDEN, 2006, p. 292; RIGOLON; GIAMBIAGI, 1999, p. 124) ${ }^{24}$.

Houve ainda um aumento do controle da utilização dos recursos públicos, tanto pela redução significativa das rendas próprias dos Estados ${ }^{25}$, alterando parcialmente aquele movimento descentralizador de recursos previsto na Constituição Federal, como pela introdução de uma série de mecanismos de controle dos gastos públicos, os quais vinculavam o acesso a novos recursos (transferências voluntárias e operações de crédito) à comprovação da correta utilização das verbas federais anteriormente repassadas (art. 25 da LRF). A restrição dos gastos públicos foi ainda objeto de importantes limitações promovidas pela LRF, destacando-se tanto a inserção da "regra de ouro" fiscal, que impede o

\footnotetext{
22 Dentre outras destacam-se: Resolução 2.003/1993 do Conselho Monetário Nacional: limita a expansão da dívida bancária pelos Estados; Lei no 9.496/1997, que instituiu o Programa de Apoio Financeiro e de Refinanciamento da Dívida dos Estados e Municípios; EC n 3/1999: proíbe a emissão de novas dívidas pelos Estados; Resolução 2.003/1993 do Conselho Monetário Nacional: limita a expansão da dívida bancária pelos Estados; LC 101/2000, denominada Lei de Responsabilidade Fiscal, dentre outras.

23 Sobre a necessidade de fortalecimento do ente central para combater a indisciplina fiscal dos entes subnacionais ver: Rodden (2006, p. 110), Cabral (2015, p. 246) e Inman (2003, p. 41).

${ }^{24}$ Os bancos estaduais foram responsáveis em 1988 e 1989, respectivamente, por 28,2\% e $46 \%$ do total dos empréstimos e financiamentos concedidos aos estados e municípios, mantendo em 1988,77,8\% do valor total de suas operações de crédito concentradas no setor público (LOPREANO, 2010, p. 126).

${ }^{25}$ Houve uma redução de $40 \%$ (na CF 1988) para 24,6\% (em 2004), do percentual total de tributos distribuídos aos Estados (BARBOSA, 2014, p. 48).
} 
endividamento para custeio de despesas correntes ${ }^{26}$, como a instituição de limites globais para gastos com pessoal.

Assim, o compromisso legal de não resgate, a limitação de gastos públicos, a inserção de instrumentos de controle da aplicação dos recursos públicos e de acesso a novos recursos deveriam reestruturar a matriz de incentivos. Evitar-se-ia um futuro comportamento oportunista dos Estados, induzindo a disciplina fiscal dos entes subnacionais.

Mas voltemos ao jogo do resgate. Como visto, no grafo do jogo, o comportamento do ente subnacional é especialmente afetado pelo tipo de ente central com o qual ele se relaciona. Na estrutura de incentivos estabelecida por Rodden, duas condicionantes são essenciais para induzir a responsabilidade fiscal do ente subnacional: o compromisso de não resgate do ente central e a dificuldade de acesso a recursos não previstos no orçamento do ente subnacional, a denominada restrição orçamentária flexível. Tais restrições deveriam induzir um ajuste imediato por parte dos Estados, evitando que pequenas crises fiscais fossem prolongadas mediante recursos extraordinários ou empréstimos internos ou externos.

Ambos os requisitos foram inseridos no ordenamento jurídico brasileiro tanto pela LRF, como pelas demais alterações normativas, que visaram tornar mais rígido o orçamento dos Estados, com o intuito de evitar novas crises fiscais. Com isso, pretendeu-se extinguir aquela perigosa simbiose presente na estrutura federalista brasileira.

Conforme o grafo descrito no item 1.2, a indução reversa irá indicar tanto que os resgates parciais se tornaram mais difíceis de ocorrer, diante das novas restrições orçamentárias de acesso a recursos, como também que um futuro resgate por parte da União seria improvável e extremamente custoso politicamente. Ademais, a LRF inseriu um incentivo direto e imediato para que os Estados mantivessem suas contas saneadas, ao condicionar o repasse de transferências voluntárias e o aval da União para obtenção de crédito externo à ausência de dívidas estaduais perante o ente central.

Nesse contexto, a LRF era vista como uma das mais importantes alterações no sistema federalista brasileiro, capaz de reconstruir a matriz de incentivos desse complexo contrato federal, de modo a induzir a responsabilidade fiscal dos Estados.

Entretanto, recentes notícias sobre o aprofundamento da crise em diversos Estados parecem contestar todo o arcabouço teórico exposto até o presente momento. Afinal, será possível identificar alguma falha

${ }^{26}$ LC 101/2000, Art. 12. (...) $\S 2^{\circ}$ O montante previsto para as receitas de operações de crédito não poderá ser superior ao das despesas de capital constantes do projeto de lei orçamentária. 


\section{REVISTA ESTUDOS INSTITUCIONAIS}

que justifique o fracasso das alterações legislativas? É o momento de virarmos os olhos para um terceiro jogador: o garantidor dos acordos, o Poder Judiciário.

\section{O STF: ÁRBITRO OU JOGADOR DAS NOVAS RODADAS DE RESGATES}

É interessante observar que as mudanças estruturais visaram essencialmente o fortalecimento da União, pela centralização de responsabilidade, tanto na arrecadação como no controle da utilização dos recursos públicos. Manteve-se a premissa de que quanto mais o ente central é responsável por grande parcela dos orçamentos locais, maior é a tendência em se buscar uma solução no próprio ente central, nesse caso, na União (RODDEN, 2006, p. 96).

Ademais, considerando a ampla competência legislativa da União, o eventual ajuste fiscal dos entes subnacionais permanece vinculado a inúmeras normas federais, o que gera uma dificuldade de redução dos gastos públicos, em especial no âmbito previdenciário e de pagamento de pessoal do serviço público.

Tais problemas deveriam ser compensados pelos instrumentos de limitação de gastos e de controle no acesso e na correta utilização dos recursos públicos, criando tanto incentivos para o comportamento cooperativo dos entes subnacionais como custos para sua indisciplina fiscal. Desse modo, a União disporia de mecanismos legais necessários para impor sucessivos pequenos ajustes fiscais sempre que observada a irresponsabilidade dos Estados. Por fim, ainda que os demais mecanismos falhassem, restava a promessa de não resgate entalhada na LRF.

Hipoteticamente, podem ser levantadas duas causas primordiais para o fracasso das mudanças legislativas: uma estrutural, que seria a ausência de alterações suficientes na matriz de incentivos; e outra conjuntural, decorrentes da não concretização dessa nova matriz.

Nesse contexto, entende-se que a estrutura até aqui apresentada tenha ignorado um terceiro elemento essencial, qual seja, o juiz. De fato, o Judiciário possui como função primordial garantir o cumprimento dos acordos privados (os contratos) e dos acordos políticos (as leis) (GICO JR., 2013, p. 441). Teoricamente, o Judiciário representaria uma garantia de que toda a estrutura de incentivos estabelecida originariamente nos acordos seria efetivamente implementada, reduzindo o problema da desconfiança recíproca. De outro lado, acaso o Judiciário decidisse por 


\section{O SUPREMO TRIBUNAL FEDERAL COMO ÁRBITRO OU JOGADOR?}

negar ou reduzir a normatividade da lei, a matriz poderia se alterar completamente.

O Judiciário exerce função de tamanha relevância no federalismo, sendo possível afirmar que sua existência seria uma das condições indispensáveis para a manutenção do equilíbrio federativo ${ }^{27}$. Assim, caberia ao Judiciário, como órgão independente, evitar que aqueles dois dilemas federalistas ${ }^{28}$ se concretizem sendo sua função primordial garantir a divisão e o compartilhamento de poderes e competências constitucionalmente estabelecidos (ARONEY; KINCAID, 2016, p. 04). Em outras palavras, como árbitro do federalismo, o Judiciário - em regra por meio da Suprema Corte - deve impedir o governo central amplie seu próprio poder e também incentivar a cooperação dos entes subnacionais, reconhecendo e punindo eventuais comportamentos oportunistas. Resta indagar o impacto do STF na estruturação dos incentivos desse complexo contrato que chamamos de federalismo.

Por certo, o presente artigo não comporta uma análise exaustiva da jurisprudência do STF sobre federalismo. Nosso foco recai sobre um dos incentivos inseridos pela LRF, qual seja, a possibilidade de a União negar a transferência de recursos e o acesso a crédito externo acaso não observadas as condicionantes previstas no artigo $25, \S 1^{\stackrel{0}{ }}$, da citada lei ${ }^{29}$.

\footnotetext{
27 Nesse sentido, "[o]ur central thesis is that durable federal arrangements are possible only if two conditions hold. First, national forces must be structurally restrained from infringing on the federal bargain. Secondly, provincial temptations to renege on federal arrangements must be checked as well, possibly by the application of legal rules enforced by an independent judiciary" (BEDNAR; ESKRIDGE; FEREJOHN, 2001, p. 226).

${ }^{28} 1$. o que impede o governo central de aumentar seu próprio poder? 2. O que impede os entes subnacionais de adotarem comportamentos oportunista, não cooperando para a manutenção do federalismo? (WEINGAST; FIGUEIREDO JR., 2005, p. 105).

${ }^{29}$ Art. 25. Para efeito desta Lei Complementar, entende-se por transferência voluntária a entrega de recursos correntes ou de capital a outro ente da Federação, a título de cooperação, auxílio ou assistência financeira, que não decorra de determinação constitucional, legal ou os destinados ao Sistema Unico de Saúde.

$\S 1$ o São exigências para a realização de transferência voluntária, além das estabelecidas na lei de diretrizes orçamentárias:

I - existência de dotação específica;

II - (VETADO)

III - observância do disposto no inciso X do art. 167 da Constituição;

IV - comprovação, por parte do beneficiário, de:

a) que se acha em dia quanto ao pagamento de tributos, empréstimos e financiamentos devidos ao ente transferidor, bem como quanto à prestação de contas de recursos anteriormente dele recebidos;

b) cumprimento dos limites constitucionais relativos à educação e à saúde;
} 


\section{REVISTA ESTUDOS INSTITUCIONAIS}

O dispositivo não apenas pune o Estado irresponsável (que não presta contas dos recursos ou extrapola os limites constitucionais de gastos), como também recompensa com novos recursos aquele Estado que mantem sua saúde fiscal.

É o que se desenvolve na próxima subseção.

\section{A LRF: Restaurando os incentivos para a disciplina fiscal}

Como visto, a LRF estabeleceu que a União somente poderá celebrar um contrato de transferência voluntária de recursos ou avalizar a obtenção de crédito externo, se o Estado comprovar que não possui qualquer inadimplência perante a União ${ }^{30}$.

Assim, a despeito do cenário de dependência dos entes federativos, a estrutura de incentivos estabelecida pela LRF tende a gerar cooperação, na medida em que a restrição de acesso dos Estados a recursos internos e externos aumenta os custos de descumprimento do contrato, conferindo à União a possibilidade de retaliar na rodada que se segue ao comportamento oportunista.

De posse dessa informação, a ação racional do Estado seria a de cumprir todos os requisitos impostos pela LRF, buscando dessa forma não apenas uma melhor administração dos recursos transferidos, como especialmente, o recebimento de novas e vultosas verbas oriundas da União.

Por outro lado, a verificação do cumprimento de todos os requisitos estabelecidos na lei implicou em um aumento do custo de celebração das transferências voluntárias, referente à coleta de tais informações. Com o objetivo de reduzir tal custo e assim facilitar a celebração dos contratos, a União (por intermédio da Secretaria de Tesouro Nacional) implementou um sistema que pudesse consolidar todos os dados, acerca do cumprimento ou não dos requisitos enumerados no artigo $25, \S 1^{\circ}$, da LRF.

Tal sistema foi inicialmente denominado de Cadastro Único de Convênio/CAUC e, posteriormente, substituído pelo Serviço Auxiliar de

c) observância dos limites das dívidas consolidada e mobiliária, de operações de crédito, inclusive por antecipação de receita, de inscrição em Restos a Pagar e de despesa total com pessoal;

d) previsão orçamentária de contrapartida.

30 Importa destacar que tal retaliação não pode atingir "a ações de educação, saúde e assistência social", como estabelecido pelo $\S 3^{\circ}$, do artigo 25 da LRF, o que, se por um lado, reduz a capacidade de retaliação, por outro, confere maior credibilidade à promessa de não resgate, afastando-se legalmente o problema de comprometimento da União em relação ao Estado (RODDEN; ESKELAND; LITVACK, 2003, p. 9-12). 
Informações de Transferências Voluntárias/SIAT. É essencialmente um serviço informatizado, de atualização diária, que tem por objetivo exclusivo simplificar a verificação do atendimento de 13 dos 22 requisitos fiscais previstos na LRF para a transferência voluntária de recursos da União e obtenção de crédito externo.

Estabelecido tal sistema, sempre que um Estado pretendesse receber novas transferências voluntárias ou obter um crédito externo, a União poderia acessar o CAUC/SIAT e em caso de inadimplemento, a União deveria legalmente negar o acesso a tais recursos. Em caso de conflito, a questão seria submetida ao STF por força do artigo 102, inciso I, alínea f , da $\mathrm{CF} / 88$.

Resta expormos como o STF resolveu o citado conflito federativo.

\section{O STF: a desconstrução da matriz de incentivos}

Apesar de o STF ser uma instituição muito estudada no Brasil, a construção do presente artigo fez-se sob duas importantes premissas: a escassez de doutrina pátria (GIBSON, 2004) e de pesquisas sobre o STF e seu papel no jogo do resgate ${ }^{31}$. No que se refere ao centro constitucional de disputa federativa, momento no qual o STF se transforma no denominado tribunal da federação não foi possível localizar nenhuma pesquisa sobre o tema.

Do levantamento dos dados realizado ${ }^{32}$, foi possível observar que o conflito entre a União e os Estados ou o Distrito Federal exsurge em somente $41,4 \%$ do total das ações analisadas ${ }^{33}$. Nesse conjunto de ACOs

31 Dentre os estudos que analisam a correlação entre federalismo e controle de constitucionalidade destacam-se: Paixão (2007), Condeixa (2007), Camargo (2009), Pereira (2010), Benvindo e Costa (2014), Barbosa (2014). Há apenas dois estudos correlatos (ARLOTA; GAROUPA, 2014; ARLOTA, 2015) que ampliam tal pesquisa a outras espécies processuais, entretanto, a análise se desenvolves sobre o enfoque dos reflexos do processo de nomeação dos Ministros do STF sobre suas respectivas decisões acerca do conflito federativo. Quanto à análise da jurisprudência do STF sob o enfoque da análise econômica destaca-se Ferreira, Meneguin e Bugarin (2017) que, a despeito de ser o estudo que mais se aproxima da argumentação aqui desenvolvida, restringe-se à decisão proferida na ADI 1.292.

${ }^{32}$ Em sua pesquisa de doutorado, a autora deste artigo analisou todas as Ações Cíveis Originárias ajuizadas perante o Supremo Tribunal Federal após a Constituição de 1988 até 31 de dezembro de 2017, totalizando 2704 ações estudadas. Desse total de ações analisadas, observou-se que 161 eram erro de autuação, restando a amostra no total de 2.533 .

${ }^{33}$ Das 2.533ACOs já analisadas, somente 1050 eram conflitos travados entre a União e os Estados e o Distrito Federal. Dentre essas 1050, o STF afastou a existência de conflito federativo em 216, ao argumento de se tratar de questão meramente patrimonial ou não estar configurado risco ao equilíbrio federativo. Entretanto, o STF somente 


\section{REVISTA ESTUDOS INSTITUCIONAIS}

em que são parte a União e os Estados e/ou DF, o STF afastou sua competência em $20,5 \%$ dos casos. Assim, observando-se apenas o conflito federativo entre União e Estados, nos quais já houve decisão pelo Supremo Tribunal Federal, os dados demonstram que aproximadamente $76,5 \%$ das ACOs tratam de matérias que se relacionam diretamente com a transferência de recursos da União para os Estados ${ }^{34}$.

De outro lado, aproximadamente $66 \%$ dos conflitos federativos, entre União e Estado, tratam especificamente da LRF, destacando-se a discussão que envolvem os cadastros restritivos da União, os quais visam efetivar as condicionantes previstas na LRF, objeto do presente artigo.

Como já ressaltado, referida lei estabeleceu inúmeras condicionantes fiscais para que o Estado acesse novos recursos, seja por meio de transferência voluntária, seja por obtenção de crédito externo. Entretanto, ao ser acionado para decidir acerca da possibilidade da União se recusar a efetuar os repasses de verbas com fundamento nas restrições impostas pela LRF, o STF deferiu as liminares em aproximadamente $92,6 \%$ das ações em que o pedido cautelar foi analisado ${ }^{35}$, determinando o repasse de verbas independentemente da existência de pendências legais. Quase dez anos depois, o STF julgou, pela primeira vez, o mérito da questão estabelecendo importantes restrições à incidência da LRF.

Inicialmente, duas questões de mérito foram decididas. A primeira refere-se a forma de cumprimento dos princípios do contraditório e da ampla defesa para fins de inscrição do Estado em cadastros de inadimplência, tendo sido afirmada a necessidade de julgamento da tomada de contas especial pelo Tribunal de Contas da União. Também restou decidido que, em observância ao princípio da intranscendência

reconheceu sua competência 715 ACOs, quando houve julgamento de mérito ou cautelar reconhecendo a competência.

34 Dessas 1050 ACOs, em 715 ACOs foi proferida decisão de mérito ou liminar reconhecendo, de forma expressa ou implícita o conflito federativo. Dessas 715 ACOs, 472 tratam do descumprimento pelos Estados dos artigos 25 e 40 da LRF (CAUC) e mais 75 ACOs discutem outras questões relacionadas a repasse de verbas da União para os Estados/DF. Destacam-se os seguintes temas: formas de cálculo de verbas que impactam a transferência de recursos (Fundef, refinanciamento de dívidas e Receita Líquida Real), além da já citada recusa da União em repassar verbas voluntárias e garantir operação de crédito, quando os entes descumprem os requisitos previstos nos artigos 25 e 40 da LRF (CAUC).

${ }^{35}$ Das 472 ações envolvendo as restrições impostas pela LRF, em especial o CAUC, o STF analisou o pedido cautelar em 433 delas, deferindo a liminar em 401. Interessante destacar que a liminar somente foi expressamente indeferida em 32 dos processos analisados. Nas demais ações o pedido de liminar não foi analisado ou não foi possível localizar a decisão. 
subjetiva das sanções, o atual governador não pode ser prejudicado em razão de inadimplência ocorrida em gestão anterior.

Ademais, ainda que atendidas essas qualificadoras estabelecidas pelo STF, resta a análise do fundamento principal para o deferimento de liminares, e até mesmo para a procedência de mérito das ações originárias, que consiste no "risco de comprometimento de execução de políticas públicas" 36 .

Observa-se que a jurisprudência retirou parcela significativa da normatividade da LRF, facilitando o acesso dos Estados ao crédito e flexibilizando sua restrição orçamentária. Assim, ao reduzir a possibilidade de a União recusar a transferências de verbas diante de inadimplências dos Estados, referida jurisprudência alterou a matriz de incentivos desenhada na reconstrução do federalismo brasileiro após a crise fiscal dos anos 1990.

Ademais, o STF negou à União a possibilidade de um controle imediato e efetivo não apenas sobre os recursos repassados, mas especialmente em relação à saúde fiscal dos Estados. Ou seja, a União não mais possui um instrumento de imposição de pequenos ajustes fiscais mediante a restrição dos Estados a novos recursos.

O STF ignorou a principal preocupação exposta por Hamilton, consistente no perigo da construção de um sistema em que o centro é simplesmente incapaz de controlar os seus membros.

\footnotetext{
${ }^{36}$ (...) BLOQUEIO DE RECURSOS CUJA EFETIVAÇÃO COMPROMETE A EXECUÇÃO, NO ÂMBITO LOCAL, DE PROGRAMA ESTRUTURADO PARA VIABILIZAR A IMPLEMENTAÇÃO DE POLÍTICAS PÚBLICAS. O Supremo Tribunal Federal, nos casos de inscrição de entidades estatais, de pessoas administrativas ou de empresas governamentais em cadastros de inadimplentes organizados e mantidos pela União, tem ordenado a liberação e o repasse de verbas federais (ou, então, determinado o afastamento de restrições impostas à celebração de operações de crédito em geral ou à obtenção de garantias), sempre com o propósito de neutralizar a ocorrência de risco que possa comprometer, de modo grave e/ou irreversível, a continuidade da execução de políticas públicas ou a prestação de serviços essenciais à coletividade. Precedentes. (STF, ACO 1990, Relator Ministro Celso de Mello, Plenário, julgamento em 17/06/2015).
} 


\section{REVISTA ESTUDOS INSTITUCIONAIS}

\section{CONCLUSÕES}

Do exposto, foi possível observar que não é qualquer estrutura institucional descentralizada capaz de produzir as benesses do federalismo. No caso brasileiro, um dos principais vícios observado no sistema federalista pode ser creditado ao desenho constitucional de 1988. Ele estabeleceu um verdadeiro paradoxo federalista no qual as competências e serviços permanecem centralizadas na União, havendo um impulso de descentralização voltado à distribuição de verbas, causando um desequilíbrio sistêmico na estrutura.

A análise dessa estrutura sob o enfoque do jogo do resgate demonstrou que referido desenho induziu um comportamento fiscalmente irresponsável dos Estados, culminando em resgate fiscal pela União. A mudança dessa matriz de incentivos foi o foco das alterações normativas pós crises fiscais dos anos 1990. A nova estrutura federalista foi construída sob a necessidade de se impor severas restrições orçamentárias aos Estados. Aumentou-se o controle fiscal da União e impediu-se o acesso a novos recursos. A impossibilidade de resgate restou ainda expressamente entalhada na LRF.

A emergência de novas e mais profundas crises fiscais deslocaram o olhar para um terceiro jogador, o Poder Judiciário. Entretanto, o que se observou foi que, ao invés de garantir a execução do contrato político, o STF optou por retirar parcela considerável da normatividade da LRF. Implodiu-se um dos pilares fundamentais da nova estrutura, qual seja, a restrição de acesso a recursos por parte dos Estados. De fato, o movimento de centralização e controle das verbas ocorrido no ajuste fiscal dos anos 1990 foi parcialmente revertido pelo STF, restaurando a flexibilidade da restrição orçamentária estadual.

Por certo que tal análise não é capaz de esgotar todos os motivos que levaram às atuais crises fiscais. Porém, é suficiente para demonstrar o potencial impacto do STF sobre o federalismo fiscal, como um dos novos players do jogo do resgate. 


\section{REFERÊNCIAS}

ABRUCIO, Fernando Luiz. Os barões da federação. Lua Nova, n. 33, p. 165-190, 1994.

ARLOTA, Carolina; GAROUPA, Nuno. Addressing Federal Conflicts: An Empirical Analysis of the Brazilian Supreme Court, 1988-2010. Rev. L \& Econ., v. 10, p. 137-160, 2014.

ARLOTA, Carolina. The Interplay of judicial review and federalism choices in Brazil after Republican Constitution of 1988. 2015. Tese (Doutorado em Direito), University of Illinois at Urbana-Champaign, Illinois/Estados Unidos da América, 2015.

ARONEY, Nicholas; KINCAID, John. Introduction. In: ARONEY, N. ; KINCAID, J. (eds.). Courts in federal countries: Federalists or unitarists? Toronto: University of Toronto Press, p. 03-28, 2016.

BAIRD, Douglas G.; GERTNER, Robert H.; PICKER, Randal C. Game Theory and the Law. Cambridge: Havard University, 1994.

BARBOSA, Leon Victor de Queiroz. Guerra Fiscal e o Ativismo Judicial Negativo: Mapeando o Conflito Federativo no Supremo Tribunal Federal. Revista Política Hoje, 1. ed., v. 23, p. 43-66, 2014.

BEDNAR, Jennifer L.; ESKRIDGE, William; FEREJOHN, John A. A Political Theory of Federalism. In: FEREJOHN, John; RAKOVE, Jack; RILEY, Jonathan (eds.). Constitutions and Constitution. Cambridge: University Press, 2001.

BENVINDO, Juliano Zaiden; COSTA, Alexandre Araújo. A Quem Interessa o Controle Concentrado de Constitucionalidade? O Descompasso entre Teoria e Prática na Defesa dos Direitos Fundamentais (working paper). Brasília: Universidade de Brasília, 2014. 


\section{REVISTA ESTUDOS INSTITUCIONAIS}

Disponível em: <http://ssrn.com/abstract=2509541>. Acesso em: 20 ago. 2016

BESFAMILLE, Martin; LOCKWOOD, Ben. Bailouts in federations: Is a hard budget constraint always best? International Economic Review, v. 49, n. 2, p. 577-593, 2008.

BRASIL. ASSEMBLEIA NACIONAL CONSTITUINTE. Ata da $\mathbf{1 3}^{\mathbf{a}}$ Reunião, extraordinária, destinada à votação do anteprojeto e emendas, realizada em 22-5-87, Brasília, DF, jun 1987. Disponível em: $<$ http://imagem.camara.gov.br/Imagem/d/pdf/sup81anc20jun1987.pdf\#p age $=96>$. Acesso em: 28 de nov. 2018.

BRASIL. Supremo Tribunal Federal. Ação Cível Originária 1990/AC. Autor: Estado do Acre. Réu: União. Rel.: Min. Celso de Mello. Distrito Federal, 17 de junho de 2015. Disponível em:

$<$ http://portal.stf.jus.br/processos/detalhe.asp?incidente=4275957>. Acesso em: 28 nov. 2018.

CABRAL, Nazaré da Costa. Teoria do Federalismo Financeiro. Coimbra: Almedina, 2를. 2015.

CAMARGO, Nilo Marcelo de Almeida. A forma federativa de estado e o Supremo Tribunal Federal pós-Constituição de 1988. 2009. Dissertação (Mestrado em Direito), Pontifícia Universidade Católica do Rio Grande do Sul, Rio Grande do Sul, 2009.

CONDEIXA, Fábio de Macedo Soares Pires. Controle Judicial e Federalismo no Brasil: Supremo Tribunal Federal vs. Legislativos Estaduais. 2007. Dissertação (Mestrado em Ciência Política) Universidade Federal do Rio de Janeiro, Rio de Janeiro, 2007. 
FERREIRA, Debora; MENEGUIN, Fernando; BUGARIN, Maurício. Responsabilidade fiscal, a atuação do Poder Judiciário e o comportamento estratégico dos governantes. Economics and Politics Working Paper, n. 74, 2017.

FILIPOV, Mikhai; ORDESHOCK, Peter; SHVETSOVA, Olga. Designing Federalism: A Theory of Self-Sustainable Federal Institutions. Cambridge University Press, 2004.

GIBSON, Edward. Federalism and Democracy in Latin America: Theoretical Connections and Cautionary Insights. Baltimore : Johns Hopkins University, 2004.

GICO JR., Ivo Teixeira. O Capital Jurídico e o Ciclo da Litigância. Revista Direito GV, v. 9, n. 2, p. 435-464, 2013.

GOODSPEED, Timothy J. et al. Bailouts and soft budget constraints in decentralized government: A synthesis and survey of an alternative view of intergovernmental grant policy. Hacienda Pública Española/Review of Public Economics, p. 02-30, 2016.

HAMILTON, Alexander; MADISON, James; JAY, John. Os artigos federalistas 1787-1788. Tradução Maria Luiza X. Borges. Rio de Janeiro: Nova Fronteira, 1993.

INMAN, Robert. Local Fiscal Discipline in U.S. Federalism. In: RODDEN, Jonathan; ESKELAND, Gunnar; LITVACK, Jennie (eds.). Decentralization and the Challenge of Hard Budget Constraints. Cambridge: MIT Press, p. 34-84, 2003.

LIMA, Kelsiane de Medeiros. Federalismo e Desenvolvimento. Cooperação entre os entes federados - limites, direitos e deveres. 2010. Dissertação (Mestrado em Direito), Universidade Federal do Rio Grande do Norte, Rio Grande do Norte, 2010. 


\section{REVISTA ESTUDOS INSTITUCIONAIS}

LOPREANO, Francisco Luiz. O endividamento dos governos estaduais nos anos 90. Economia e Sociedade, Campinas, n. 15, p. 117-158, 2010.

MANIN, Bernard; PRZEWORSKI, Adam; STOKES, Susan. Democracy, Accountability and Representation. Cambridge: Cambridge University Press, 1999.

PAIXÃO, Leonardo André. A função Política do Supremo Tribunal Federal. 2007. Tese (Doutorado em Direito do Estado), Universidade de São Paulo, São Paulo, 2007.

PEREIRA, Fábio Franco. A federação no constitucionalismo brasileiro. 2010. Dissertação (Mestrado em Direito do Estado), Universidade de São Paulo, São Paulo, 2010.

RIGOLON, Francisco; GIAMBIAGI, Fábio. A Renegociação das dívidas e o regime fiscal dos Estados. A economia brasileira nos anos, v. 90, p. 111-144, 1999.

RODDEN, Jonathan. Hamilton's Paradox: The Promise and Peril of Fiscal Federalism. Cambridge: Cambridge, 2006.

RODDEN, Jonathan; WIBBELS, Erik. Beyond the fiction of federalism: Macroeconomic management in multitiered systems. World Politics, v. 54, n. 4, p. 494-531, 2002.

RODDEN, Jonathan; ESKELAND, Gunnar; LITVACK, Jennie. Introduction and Overview. In: RODDEN, Jonathan; ESKELAND, Gunnar; LITVACK, Jennie (eds.). Decentralization and the Challenge of Hard Budget Constraints. Cambridge: MIT Press, 2003. 
SOUZA, Celina. Federalismo e Descentralização na Constituição de 1988: Processo Decisório, Conflitos e Alianças. DADOS-Revista de Ciências Sociais, v. 44, n. 3, p. 513-560, 2001.

SOUZA, Celina. Federalismo, desenho constitucional e instituições federativas no Brasil pós-1988. Revista de Sociologia e Política, n. 24, p. 105-121, 2005.

TAVARES, Marcus. Vinte anos de política fiscal no Brasil: dos fundamentos do novo regime à Lei de Responsabilidade Fiscal. Revista de Economia \& Relações Internacionais, v.4 , n. 7, p. 79-101, 2005.

TOCQUEVILLE, Alexis de. A Democracia na América. 2. ed. Belo Horizonte: Cia. Editora Nacional, 1961.

WALTER, D. M. The Nation's Growing Fiscal Imbalance. Presentation to CSIS Global Aging Forum. US Government Accountability Office, 2004.

WEINGAST, Barry; FIGUEIREDO Jr.; Rui J.P. Self-Enforcing Federalism. The Journal of Law, Economics, \& Organization, v. 21, n. 1, p. 103/135, 2005.

WILDASIN, David. Externalities And Bailouts: Hard and Soft Budget Constraints in Intergovernmental Fiscal Relations. 1997. Disponível em $<$ https://pdfs.semanticscholar.org/04e0/d12a05f925d018b77ebbecdfdeb73 8620741.pdf $>$. Acesso em: 28 nov. 2018.

RECEBIDO EM: 30/05/2018.

ACEITO EM: 19/06/2018. 